\title{
A STUDY ON THE RELATIONSHIPS AMONG PERSONALITY TRAITS, ENTREPRENEURIAL MOTIVATION AND PERFORMANCE - TAKING MICRO PHOENIX ENTREPRENEURS AS AN EXAMPLE
}

\author{
SHEAU-HWA CHEN ${ }^{1}$, TIEN-HSUN LAI ${ }^{2}$ \\ ${ }^{1,2}$ Department of Business Administration, National Dong Hwa University, Taiwan \\ schen@gms.ndhu.edu.tw, Emath10515@gmail.com
}

\begin{abstract}
Small and micro enterprises, the main foundation for Taiwan's economic development, have been affected by the global financial crises and economic storm in recent years. Along with an unstable international environment, slow economic growth, rising raw material costs; external business shifts, changing population structure, imminent industrial transformation, the micro-enterprises are facing unprecedented challenges. Therefore, the government has provided a series of subsidiary arrangements, including the Mini Phoenix Entrepreneur Loan, the focus of this study.

This study explores whether personality traits and entrepreneurial motivations have an impact on entrepreneurial performance. Questionnaires were distributed to qualified micro-phoenix entrepreneurs in five districts (north, central, southern, eastern, and outlying islands) and interviews were conducted. Out of 2,500 questionnaires distributed, 341 responded, with a $13.6 \%$ response rate. Correlation, regression, and cluster analyses were adopted to verify research hypotheses.

The empirical results show that the personality traits of micro-Phoenix entrepreneurs are related to entrepreneurial motivation; personality traits have influence on performance; entrepreneurial motivation also has a partial impact on entrepreneurial performance.

This study is intended to increase the understanding of Phoenix lenders, clarify the factors affecting Phoenix loan entrepreneurs, and then contribute to the operation and development of micro-enterprises.
\end{abstract}

Keywords. Personality traits, Entrepreneurial motivation, Entrepreneurial performance, Phoenix Venture Loan

\section{INTRODUCTION}

The foundation of Taiwan's economic development is the flourishing development of countless SMEs. The development of small and medium-sized enterprises provides opportunities for national economic growth and employment, and plays a very important role in the stability of the country. According to the 2017 SME White Paper 2016, Taiwanese SMEs accounted for $97.73 \%$ of all enterprises; SMEs accounted for $78.19 \%$ of the national employment population, indicating that SMEs are more capable of providing economic vitality and job creation in the context of Taiwan's economic development.

Among them, the proportion of micro-enterprises in Taiwan's enterprises is as high as $79.79 \%$. Therefore, the successful development of micro-enterprises has a great relationship with the growth of Taiwan's economy and the contribution of employment. However, despite such a high percentage of 
entrepreneurship, it is most important to be able to continue sustainably.

According to the industry and commerce survey conducted by SMEs every five years, the survival rate of large enterprises over 5 years is as high as $94.0 \%$, while that of micro enterprises is only $74.0 \%$, in other words, three-quarters of micro-enterprises will fade out within five years. Taking a longer timespan more than ten years, the survival rate of large enterprises is $93.5 \%$, while that of micro enterprises is reduced to 57.3\% (2014 SME White Paper). small and micro enterprises face market changes and fine it difficult to survive.

Since 1989, the Taiwan government has been committed to promoting micro-enterprise consulting. Phoenix Venture Capital is one of the most widely used sources of funding. It is interesting to inviestigate the relationships among entrepreneurial personality traits, entrepreneurial motivation and entrepreneurial performance.

\section{LITERATURE REVIEW}

\subsection{Microenterprise}

According to the project of supporting and assistance for micro and $\mathrm{SOHO}$ enterprises provided by the SMEs Department of the Ministry of Economic Affairs of Taiwan, a micro-enterprise is defined as a small and medium-sized business enterprise with under five employees (Small and Medium Enterprise Administration, Ministry of Economic Affairs, 2013) [21]. In recent years, the assistance for micro-enterprises includes pre-employment training, consulting services, marketing expertise and micro-loans. In Taiwan, since 1989, efforts have been devoted toward micro-enterprise counseling, and the "Micro-Chuanghuang Phoenix Project" in various cities is one of the most important practices.

Personality traits. Personality traits combine the characteristics of physical psychology to reflect the individual's unique personality and psychological characteristics [1] which cannot be described and understood by a single standard. Individuals may have different behaviors and attitudes or working pattern [2]. There are many different aspects in the construction of personality traits. Considering the complexity of the whole, the measurement model, the reliability and the predictive validity, Costa $\&$ McCrae (1985) [3] proposed that the five personality traits are complete compared to other personality studies [4]. In addition, after years of validation and development, Barrick \& Mount (1911) [5] have collected 117 studies and found a correlation between job performance and five personality traits, taking into account the relationship with entrepreneurs. The Big-five model of personality traits is therein adopted in the current study .

Entrepreneurship. For entrepreneurs, wealth earning is often seen as the most important motivation. However, according to the existing research results, wealth earning while starting a new business is not the only motivation, nor the most important. Other motivations such as innovation, vision, independence and challenge are more pronounced [6]. The study defines entrepreneurial motivation as the driving force for individual activities, motivating and sustaining activities to achieve work goals or achievements. The 
five dimensions suggested by Dubini (1989) [7] and Huang (2006) [8] are adopted and include: monetary desire, autonomy, social status, self-realization, and experience inheritance.

Entrepreneurial Performance. Cooper \& Artz (1995) [9] argue that entrepreneurs' self-assessment is the most basic way to measure business performance. Based on the Discrecancy Theory, they believe that satisfaction depends on the difference between the previously set goals and the subsequent performance. Research shows that entrepreneur satisfaction indicators can include initial entrepreneurial goals and expected goals, as well as the unique satisfaction characteristics of different types of entrepreneurs themselves. Chen (2005) defines the entrepreneurial performance of micro-enterprises as the ultimate result of entrepreneurs' own operations. This study uses Cooper \& Artz's (1995) [9] subjective entrepreneurial performance perspective along with Chen's definition and measures satisfaction with two categories: objective economic indicators and subjective non-economic indicators.

\section{Relationship among Personality Traits, Entrepreneurial Motivation and Entrepreneurial}

Performance. Singh \& Noble (2003) [10] believe that personality traits are one of the main reasons why a person becomes an entrepreneur. Entrepreneurs have certain psychological characteristics that form so-called specific personality traits [11]. Costa \& McCrae (1985) [3] propose five personality traits that can predict the success of an entrepreneur's success. Holland (1985) [12] proposes the personality-job fit theory by exploring the association of personality traits and job adaptability. He believes that whether a person's traits match one's career will determine job performance.

Regarding the relationship between entrepreneurs and firm performance, Poon, Ainuddin, and Junit (2006) [13] explores the impact of entrepreneurial characteristics on firm performance via path analysis to find the direct and indirect relationships of features in firm performance. The characteristics of internal control have a positive impact on company performance. Blawatt (1995) [14] points out that motivation is the main factor affecting business performance. Buttner \& Moore (1997) [15] suggests motivation is related to entrepreneurial performance after studying women entrepreneurs. The "pull" factor and the performance of entrepreneurs are reasonable. A significant correlation between entrepreneurial motivation and financial performance and self-realization sustains in enormous studies.

\section{RESEARCH METHODS}

The purpose of this study is to explore the entrepreneurial personality characteristics of micro-entrepreneurs, the differences and interrelationships between entrepreneurial motivation and entrepreneurial performance, and to analyze the basic data and characteristics of Weifeng entrepreneurs. The research framework is shown in Figure 1.

Based on the theoretical framework, three hypotheses are developed:

H1: Personality traits of entrepreneurs are related to entrepreneurial motivation.

$\mathrm{H} 2$ : Entrepreneur's personality traits have an impact on entrepreneurial performance.

H3: Entrepreneurial motivation has an impact on entrepreneurial performance. 


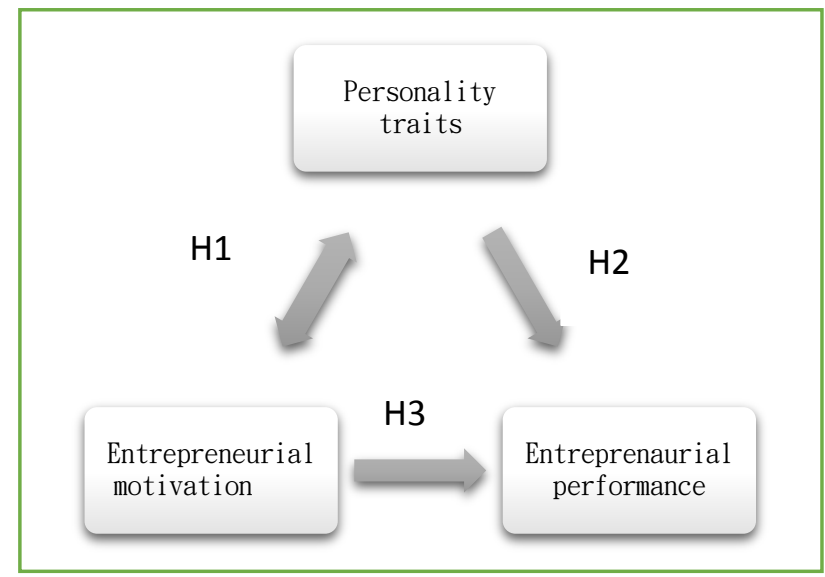

\subsection{Definition and Measurement of Study Variables}

The five-point Likert's scale was applied for the study variables of personality traits, engrepreneurial motivation, and business performance: 1-5 points from "very disagree" to "very agree".

Personality traits. Saucier's Mini-Makers short personality quality table (1994) [16] and Thompson's Mini-Five Mini-Makers short version (2008) [17] are integrated. The Chinese version of the Big English Mini-Five Mini-Makers developed by Deng, Zeng, Li and You (2011) is used as a reference.

Entrepreneurial motivation. Based on 28 variables suggested by Dubini (1989) [7], Huang's (2006) [8] extracts 17 variables for five motivational factors. These 17 variables are framed into questions.

Business performance. Questions by Venkatraman \& Ramanujam (1986) [18]; Chen (2005) [19]; Chen (2009) [20] are integrated to come up with 8 objective financial performance and major non-financial performance indicators

Background characteristics. Background information including gender, age, capital amount, number of employees, industry category, educational level, company age, and location is collected.

\subsection{Sampling and data analysis}

A survey was conducted for data collection. This study used a questionnaire survey method to sample the samples using a convenient sampling method. Questionnaires were distributed to qualified micro-phoenix entrepreneurs in five districts (north, central, southern, eastern, and outlying islands) along with interviews. Out of 2,500 questionnaires distributed, 341 responded, with a $13.6 \%$ response rate. Correlation, regression, and cluster analyses were adopted to verify research hypotheses. Descriptive statistics, correlation analysis, regression analysis and cluster analysis, through SPSS, were used.

\section{RESEARCH RESULTS}

\subsection{Descriptive statistics}

Background characteristics. The sample consists of 81 males (23.8\%) and 259 females (76.2\%), representing the majority of entrepreneurs. The entrepreneurs aged between 28 and 47 years old account 
for $71.6 \%$. One hundred and sixty-one entrepreneurs have university degrees, accounting for $47.2 \%$. Most companies have been established for 1-3 years, and have 2 employees. Over half $(53.6 \%)$ of the micro-enterprises is the type with less human resources demand, such as catering, wholesale and retail, of which the catering accounts for 39.0\%. Over half (50.7\%) of the respondents are in northern Taiwan.

Personality traits. "Stability"(3.47) and "openness" (3.36) are the highest, followed by "extroversion" (3.21) and "stringence" (3.03) and "agreeableness" (2.93).

Entrepreneurial motivation. "Autonomy" (3.99) and "monetary desire"(3.81) are the highest, followed by "self-realization" (3.72), "social status"(3.47), and "experience inheritance"(2.80).

\subsection{Correlation Analysis}

Most correlations are significant, out of which 19 significant positive correlations between the five aspects of personality traits and the five aspects of entrepreneurial motivation. Table 1 shows that openness and extroversion personality traits have the highest associated with entrepreneurial motivation. Entrepreneurial motivation is a higher self-fulfilling entrepreneur whose personality is less agreeable and extroversion and openness is higher. Entrepreneurs driven by monetary desire appear to be more stable and less inclined to be kind to others.Entrepreneurs with higher extroversion have lower entrepreneurial motivation for their monetary desire, but tend to self-realization and social status. According to the above analysis, $\mathrm{H} 1$ was established.

Table 1. Correlation analysis between two variable facets

\begin{tabular}{|c|c|l|l|l|l|l|}
\hline \multicolumn{2}{|c|}{} & \multicolumn{5}{|c|}{ Personality } \\
\cline { 3 - 7 } \multicolumn{2}{|c|}{} & Extraversion & Openness & Stability & Stringence & Agreeableness \\
\hline \multirow{4}{*}{ Motivation } & self-realization & $.281^{* *}$ & $.338^{* *}$ & $.170^{* *}$ & $.163^{* *}$ & $.150^{* *}$ \\
\cline { 2 - 7 } & monetary desire & $.200^{* *}$ & $.125^{*}$ & $.236^{* *}$ & $.161^{* *}$ & $.116^{*}$ \\
\cline { 2 - 7 } & autonomy & $.225^{* *}$ & $.302^{* *}$ & $.215^{* *}$ & $.165^{* *}$ & .095 \\
\cline { 2 - 7 } & social status & $.246^{* *}$ & $.304^{* *}$ & $.192^{* *}$ & $.159^{* *}$ & $.124^{*}$ \\
\cline { 2 - 7 } & $\begin{array}{c}\text { experience } \\
\text { inheritanc }\end{array}$ & $.239^{* *}$ & $.118^{*}$ & -.016 & $.197^{* *}$ & $.174^{* *}$ \\
\hline
\end{tabular}

\subsection{Regression Analysis}

\section{Entrepreneurial personality traits on entrepreneurial performance.}

Model 1: Y1 (objective entrepreneurial performance $)=0.294 *($ extroversion $)+0.321 *$ (openness $)+$ $0.187 *$ (stability) $+0.245 *$ (stringence) $-0.211 *$ (agreeableness).

Statistical analysis results are shown in Table 2. 
Table 2. Regression Analysis of Entrepreneur's Personality Traits on Entrepreneurial Performance (Y1)

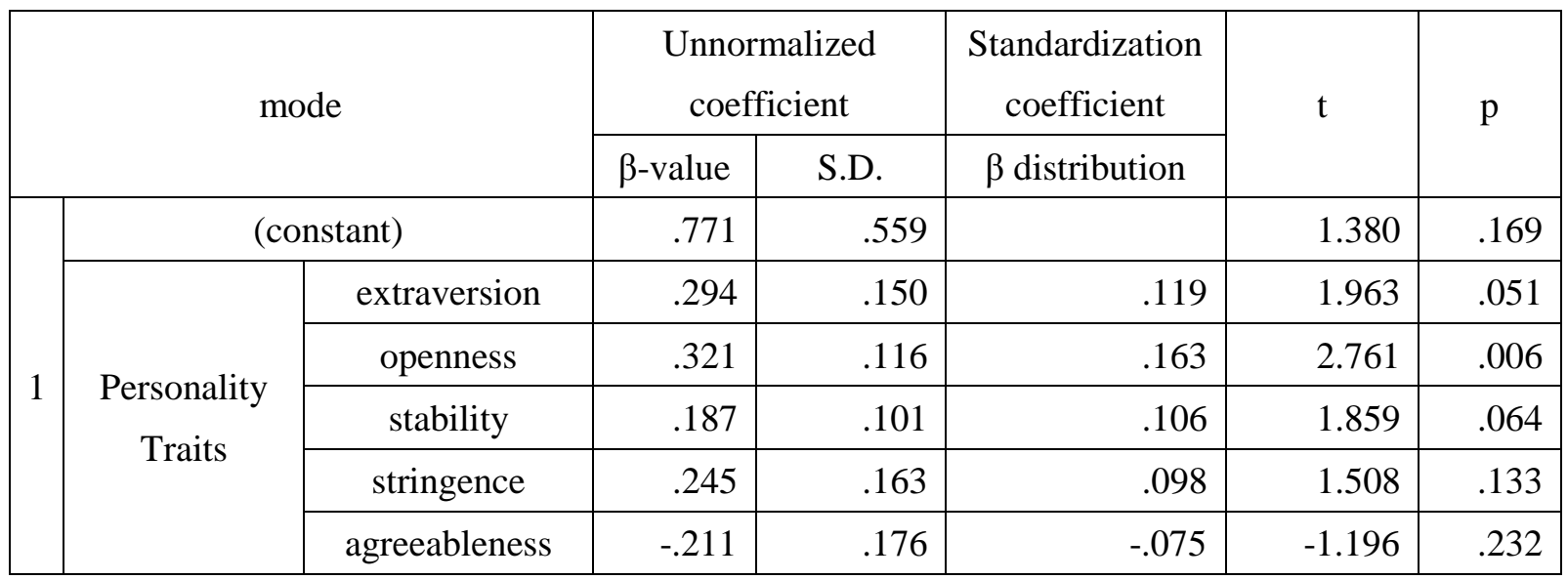

Model 2: Y2 (subjective entrepreneurial performance $)=0.281 *$ (extrover $)+0.390 *$ (openness $)+0.146$ $*$ (stability) $-0.206 *$ (stringence) $-0.181 *$ (agreeableness).

Statistical analysis results are shown in Table 3.

Table 3. Regression Analysis of Entrepreneur's Personality Traits on Entrepreneurial Performance (Y2)

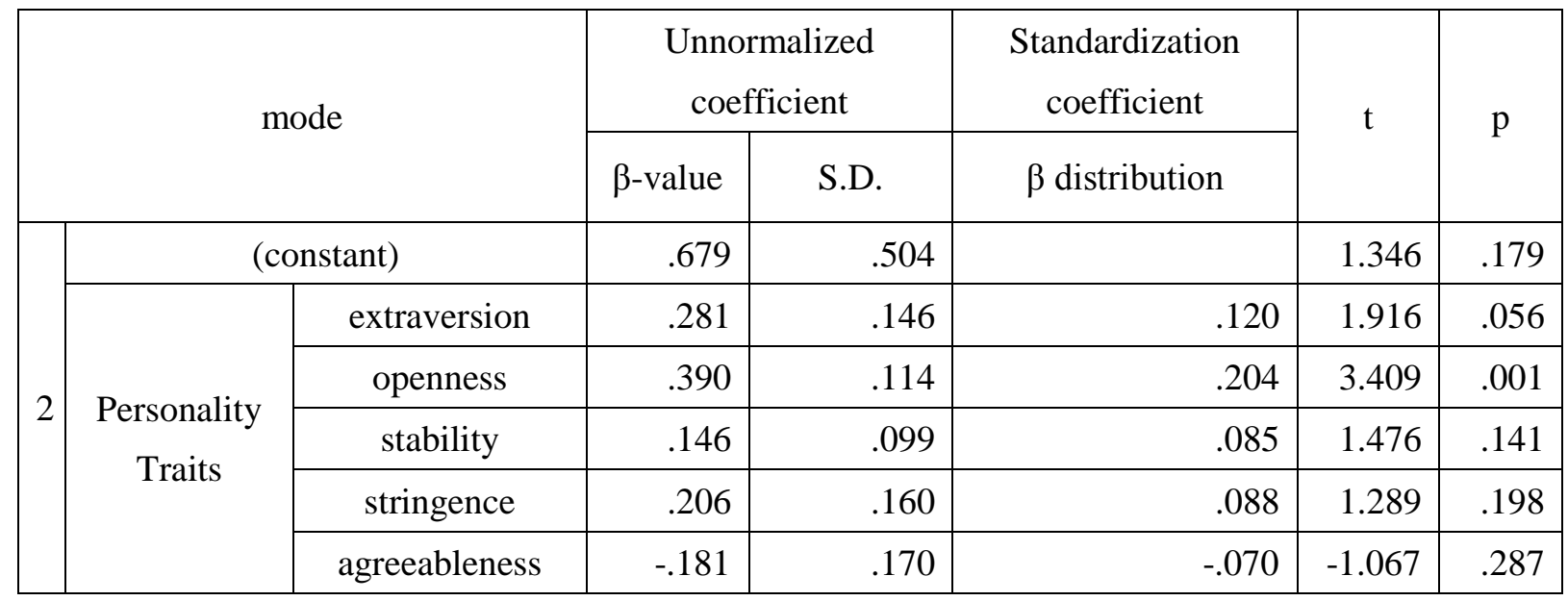

Extroversion and open personality values are significant, indicating that these two personality traits have a positive impact on objective performance. Statistics have verified that certain personality traits have a significant relationship with entrepreneurial performance. $\mathrm{H} 2$ is partially supported.

\section{Entrepreneurial Motivation on Entrepreneurial Performance.}

Model 3: Y3 (average annual operating income $)=-0.033 *$ (self-realization $)+0.090 *$ (monetary desire) $+0.250 *$ (autonomy) $+0.054 *$ (social status) $+0.045 *$ (experience inheritance) .

Statistical analysis results are shown in Table 4. 
Table 4. Regression Analysis of Entrepreneurial Entrepreneur Motivation on Objective Performance (Y3)

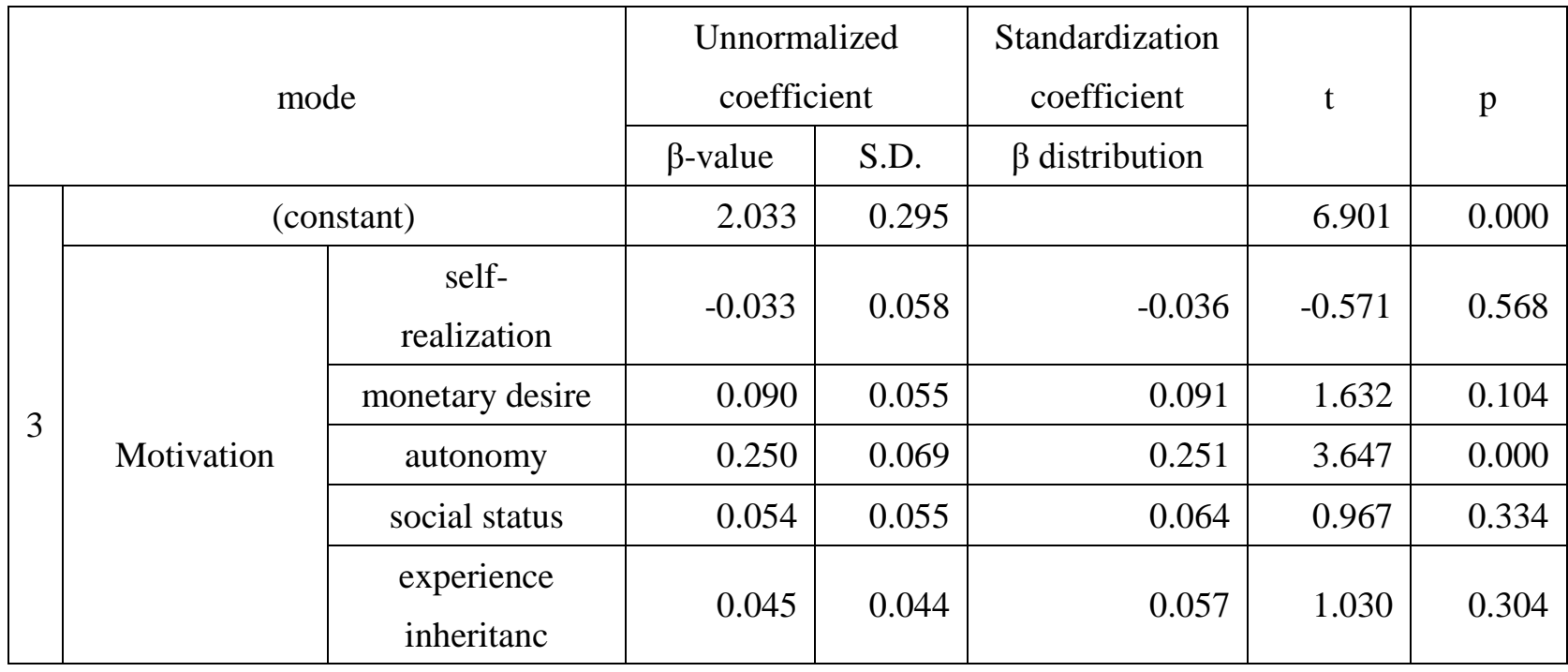

(1) Model 4: Y4 (subjective entrepreneurial performance) $=0.024 *$ (self-realization) $)+0.117 *$ (monetary desire) $+0.133 *$ (autonomy) $+0.103 *$ (social status) $+0.033 *$ (experience inheritance). Statistical analysis results are shown in Table 5.

Table 5. Regression Analysis of Entrepreneurial Entrepreneur Motivation on Entrepreneurial Performance (Y4)

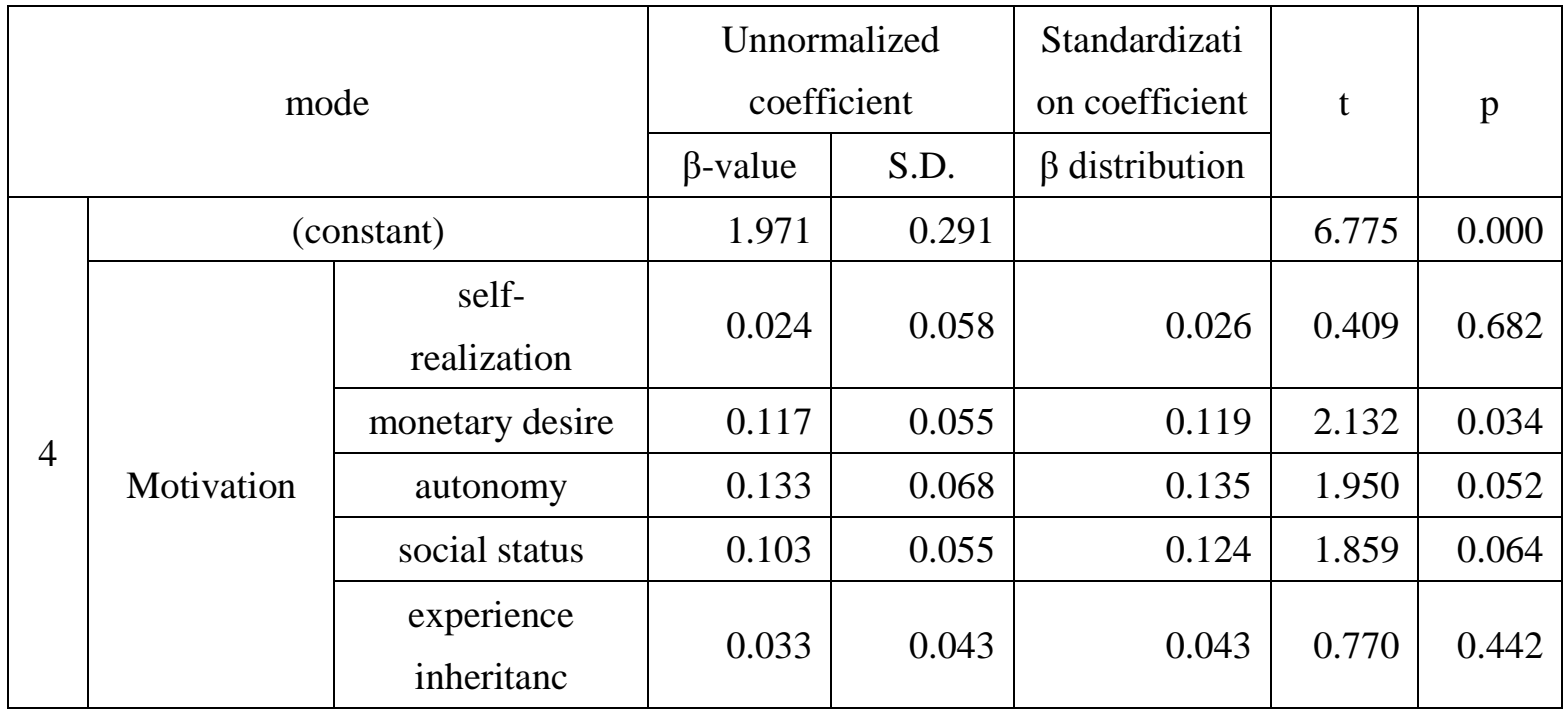

Significant influence of entrepreneurs' entrepreneurial motivation on their business performance include "autonomy" on objective as well as subjective performance, and "monetary desire" on subjective performance $\mathrm{H} 3$ is partially supported.

\subsection{Cluster Analysis}

According to the study by Costa \& McCrae (1992), the five facets divided into personality traits serve as the basis of cluster analysis. The K-means method is used for cluster analysis. The effective 
number of samples is 341 , and four clusters are detected. One-Way ANOVA is performed to characterize the differences in the personality traits of the four clusters. Statistical analysis results are shown in Table 6. The four clusters demonstrate significant differences in the five personality traits. The five facet factors of personality traits are compared and ranked among the four clusters and thereby labeled as "conservative", "confident", "innovative", and "subjective", respectively.

Table 6. Cluster Analysis of Personality Traits

\begin{tabular}{|c|c|c|c|c|c|c|c|c|c|c|c|}
\hline \multicolumn{2}{|c|}{ Cluster label } & $\mathrm{C} 1$ & Rank & $\mathrm{C} 2$ & Rank & $\mathrm{C} 3$ & Rank & $\mathrm{C} 4$ & Rank & $\mathrm{F}$ & $\mathrm{p}$ \\
\hline \multirow{5}{*}{$\begin{array}{c}\text { Personality } \\
\text { Traits }\end{array}$} & Extraversion & 3.11 & 2 & 3.22 & 3 & 3.56 & 3 & 3.15 & 3 & 40.70 & 0.00 \\
\hline & Openness & 3.04 & 3 & 3.30 & 2 & 3.84 & 1 & 3.59 & 1 & 171.82 & 0.00 \\
\hline & Stability & 3.13 & 1 & 3.94 & 1 & 3.61 & 2 & 3.38 & 2 & 173.85 & 0.00 \\
\hline & Stringence & 2.95 & 4 & 3.04 & 4 & 3.35 & 4 & 2.99 & 4 & 30.38 & 0.00 \\
\hline & Agreeableness & 2.93 & 5 & 2.92 & 5 & 3.10 & 5 & 2.87 & 5 & 10.19 & 0.00 \\
\hline \multicolumn{2}{|c|}{ Cluster name } & \multicolumn{2}{|c|}{ Conservative } & \multicolumn{2}{|c|}{ Confident } & \multicolumn{2}{|c|}{ Innovative } & \multicolumn{2}{|c|}{ Subjective } & \multicolumn{2}{|c|}{341 cases } \\
\hline
\end{tabular}

First, factor analysis is used to classify entrepreneurial motivation into five facets as the basis for cluster analysis.Secondly, using the K-means method for cluster analysis, the number of valid cases is 341, and four clusters and five entrepreneurial institutions are subjected to One-Way ANOVA to verify that each of the four clusters is in business..Lastly, the four clusters are named as "Fame". "Practical", "ideal", "autonomous". As shown in Table 7, the four clusters have significant differences in the five entrepreneurial motivation factors.

Table 7. Cluster analysis of Entrepreneurial motivation

\begin{tabular}{|c|c|c|c|c|c|c|c|c|c|c|c|}
\hline \multicolumn{2}{|c|}{ Cluster label } & $\mathrm{C} 1$ & Rank & $\mathrm{C} 2$ & Rank & $\mathrm{C} 3$ & Rank & $\mathrm{C} 4$ & Rank & $\mathrm{F}$ & $\mathrm{p}$ \\
\hline \multirow{5}{*}{ motivation } & $\begin{array}{c}\text { self- } \\
\text { realization }\end{array}$ & 2.97 & 3 & 3.24 & 2 & 4.29 & 3 & 4.15 & 2 & 79.00 & 0.00 \\
\hline & $\begin{array}{c}\text { monetary } \\
\text { desire }\end{array}$ & 4.25 & 1 & 3.28 & 3 & 4.14 & 4 & 3.88 & 4 & 33.77 & 0.00 \\
\hline & autonomy & 3.88 & 2 & 3.23 & 1 & 4.47 & 1 & 4.39 & 1 & 96.06 & 0.00 \\
\hline & social status & 2.40 & 4 & 2.94 & 5 & 4.32 & 2 & 3.93 & 3 & 153.97 & 0.00 \\
\hline & $\begin{array}{l}\text { experience } \\
\text { inheritanc }\end{array}$ & 1.71 & 5 & 3.21 & 4 & 4.00 & 5 & 2.29 & 5 & 209.83 & 0.00 \\
\hline \multicolumn{2}{|c|}{ Cluster name } & \multicolumn{2}{|c|}{ Fame } & \multicolumn{2}{|c|}{ Practical } & \multicolumn{2}{|c|}{ Ideal } & \multicolumn{2}{|c|}{ Autonomous } & \multicolumn{2}{|c|}{341 cases } \\
\hline
\end{tabular}

\section{CONCLUSION, LIMITATIONS AND RECOMMENDATIONS}

Entrepreneurial motives, it is revealed that the openness and exogenousness of entrepreneurs' personality traits are highly correlated with self-realization motives. 
In addition, it is found that entrepreneurial motivation is higher in self-realization, and its personality traits are less pleasant, and extroverted and open are more intense. Entrepreneurs who are motivated by the need for money are more stable and less emotional. Entrepreneurs with higher amenity have lower motivation to choose their own entrepreneurs, but the value of inheritance experience is higher, showing that personality traits and entrepreneurial motivation are closely related.

According to the research results, entrepreneurs with "innovative" or "subjective" personality traits and with "autonomous" or "ideal" entrepreneurial motives have better performance, possibly because they emphasize high professional innovation and self-ideal. Those with the above personality traits and entrepreneurial motivations should be encouraged to start a business. For those who have already started, they could set up a stop-loss point if they do not own appropriate personality traits and the performance is not up to expectation. Entrepreneurs who want to apply for a micro-Phoenix loan in the future should first evaluate their personality traits and entrepreneurial motives. In addition to providing loans, the government should also offer a variety of learning courses and counseling,

This study focuses on the personality traits, entrepreneurial motivation and entrepreneurial performance of micro-Phoenix loan entrepreneurs. Unfortunately, other characteristics and business scope of Phoenix entrepreneurs have not been investigated. The inclusion of other variables, such as business strategy and external environmental factors, relationship networks and non-economic performance indicators will provide a better understanding of micro-Phoenix loan entrepreneurs.

In addition, it is recommended that follow-up researchers can expand the research object, conduct research on more entrepreneurs of different types of corporate loans, and compare the differences and possible interactions and correlations.

Finally, because the level involved in entrepreneurship is very complex, the recommendations can also be studied in a qualitative way, so that you can understand the various aspects of entrepreneurs in a deeper and more complete way.

\section{REFERENCES}

[1] A. Terracciano, The Italian version of the NEO PI-R: conceptual and empirical support for the use of targeted rotation. Personality and Individual Differences, vol.35, pp. 1859-1872, 2003

[2] T. Zhang, and W. Liu, A probe into the relationship between the five personality traits and leadership ability--taking the students' associations in the university of tainan as an example. Kaohsiung Hospitality Journal, vol. 9, no.1, pp. 36-60, 2007.

[3] P.T. Costa, and R.R. McCrae, NEO PI-R professional manual. Psychological Assessment Resources. Odessa, 1992. 
[4] N. Nicholson, Personality and entrepreneurial leadership:: A study of the heads of the UK's most successful independent companies. European Management Journal, vol. 16, no. 5, pp. 529-539, 1989.

[5] M.R. Barrick, M.K. Mount, and T.A. Ju, Personality and performance at the beginning of the new millennium: what do we know and where do we go next? International Journal of Selection and Assessment, vol. 9. no.1-2, pp. 9-30, 2001.

[6] R. Amit, K.R. MacCrimmon, C. Zietsma, and J.M. Oesch, Does money matter?: Wealth attainment as the motive for initiating growth-oriented technology ventures. Journal of Business Venturing, vol.16, no.2, pp. 119-143, 2001.

[7] P. Dubini, The influence of motivations and environment on business start-ups: Some hints for public policies. Journal of Business Venturing, vol. 4, no. 1, pp. 11-26, 1989.

[8] B. Huang, The relationship among personality traits, entrepreneurial motivation, strategy and performance-an empirical study in smes in taiwan. Tainan City: N.C.K.U, 2006.

[9] A.C. Cooper, and K.W. Artz, Determinants of satisfaction for entrepreneurs. Journal of Business Venturing, vol. 10, no. 6, pp. 439-457, 1995.

[10] G. Singh, and A. DeNoble, Early retirees as the next generation of entrepreneurs. Entrepreneurship theory and practice, vol.27, no.3, 207-226, 2003.

[11 R.W. Peacock, Understanding small business, practice, theory and research. Adelaide: Bookshelf Pubnet, 1999.

[12] J.L. Holland, Making vocational choices: A theory of vocational personalities and work environments. New Jersey: Prentice-Hall, 1985.

[13] J.M. Poon, R. A. Ainuddin, and S. H. Junit, Effects of self-concept traits and entrepreneurial orientation on firm performance. International Small Business Journal, vol. 24, no. 1, 61-82, 2006.

[14] K.R. Blawatt, Defining the entrepreneur: a conceptual model of entrepreneurship. Colloque du conseil canadien de la PME et de l'entrepreneuriat, pp. 13-37, 1995.

[15] H.E. Buttne, and P.D. Moore, Women's organizational exodus to entrepreneurship: self-reported motivations and correlates with success. Journal of small business management, vol. 35, pp. 34-46, 1997.

[16] G. Saucier, Mini-Markers: A Brief Version of Goldberg's Unipolar Big-Five Markers. Journal of Personality Assessment, vol. 63, no. 3, pp. 506-516, 1994.

[17] E. R. Thompson, Development and validation of an international english big-five mini-markers. Personality and Individual Differences, vol. 45, no. 6, pp. 542-548, 2008. 
[18] N. Venkatraman, and V. Ramanujam, Measurement of business performance in strategy research: a comparison of approaches. The Academy of Management Review, vol.11, no. 4, pp. 801-814, 1986.

[19] L. Chen, Research on the influence of organizational entrepreneurship and entrepreneurial opportunity identification model. New Taipei City: T.K.U, 2006.

[20] J. Chen, Research on the relationship between entrepreneurial family traits, entrepreneurial resources, entrepreneurial strategies, social networks, external environment and entrepreneurial performance: a case study of sme entrepreneurs in eastern and northern tai. Yilan County: N.I.U, 2009.

[21] Small and Medium Enterprise Administrationof Ecnomic AffairMinistry. (2014). 2014 SME White Paper.

Received on February $1^{\text {st }}$, 2019

Accepted on March 25 $5^{\text {th }}, 2019$ 